\title{
Selective Prostacyclin Receptor Agonist Selexipag, in Contrast to Prostacyclin Analogs, Does Not Evoke Paradoxical Vasoconstriction of the Rat Femoral Artery
}

\author{
Keith Morrison, Franck Haag, Roland Ernst, Marc Iglarz, and Martine Clozel \\ Drug Discovery Department, Idorsia Pharmaceuticals Ltd., Allschwil, Switzerland \\ Received November 15, 2017; accepted March 16, 2018
}

\begin{abstract}
Selexipag [2-\{4-[(5,6-diphenylpyrazin-2-yl)(isopropyl)amino]butoxy $\}-N$-(methylsulfonyl)acetamide] is a selective nonprostanoid prostacyclin $\left(\mathrm{PGI}_{2}\right.$ ) receptor (IP receptor) agonist that is approved for the treatment of pulmonary arterial hypertension (PAH). In contrast to selexipag, $\mathrm{PGI}_{2}$ analogs used in the clinic are nonselective agonists at prostanoid receptors and can also activate contractile prostaglandin $\mathrm{E}$ receptor $3\left(\mathrm{EP}_{3}\right)$ receptors. Leg pain is a common side effect in patients receiving treatment with $\mathrm{PGI}_{2}$ analogs and peripheral vasoconstriction can be responsible for side effects related to muscular ischemia. This study tested the hypothesis that $\mathrm{PGI}_{2}$ analogs could cause paradoxical vasoconstriction of the femoral artery via $\mathrm{EP}_{3}$ receptor activation but that only vasorelaxation would be observed in response to selexipag and its active metabolite ACT-333679 [\{4-[(5,6-diphenylpyrazin-2-yl)(isopropyl)amino]butoxy\}acetic acid]. Selexipag and ACT-333679 relaxed rings of the isolated rat femoral artery contracted with either
\end{abstract}

prostaglandin $\mathrm{F}_{2 \alpha}\left(\mathrm{PGF}_{2 \alpha}\right)$ or the $\alpha_{1}$ adrenoceptor $\left(\alpha_{1} \mathrm{AR}\right)$ agonist phenylephrine. ACT-333679 also inhibited contraction of the femoral artery to sympathetic nerve stimulation. In contrast, $\mathrm{PGI}_{2}$ analogs (iloprost, beraprost, and treprostinil) caused additional contraction of arterial rings precontracted with phenylephrine, which was reverted to relaxation by antagonism of $\mathrm{EP}_{3}$ receptors. Treprostinil augmented contraction of the femoral artery to sympathetic nerve stimulation in an $\mathrm{EP}_{3}$ receptor-dependent manner. Mechanistically, concomitant $\mathrm{EP}_{3}$ and $\alpha_{1} \mathrm{AR}$ receptor activation synergistically constricted femoral arteries. It is concluded that selexipag and ACT-333679 are vasorelaxants of the rat femoral artery and, unlike $\mathrm{PGl}_{2}$ analogs, do not cause paradoxical vasoconstriction via activation of $\mathrm{EP}_{3}$ receptors. $\mathrm{EP}_{3}$ receptor-mediated vasoconstriction may contribute to the well documented peripheral muscle pain reported in patients with $\mathrm{PAH}$ receiving $\mathrm{PGl}_{2}$ analogs. Leg pain may be less in patients treated with selexipag.

\section{Introduction}

Selexipag [2-\{4-[(5,6-diphenylpyrazin-2-yl)(isopropyl)amino]butoxy\}- $N$-(methylsulfonyl)acetamide] is a selective and orally bioavailable prostacyclin $\left(\mathrm{PGI}_{2}\right)$ receptor (IP receptor) agonist (Kuwano et al., 2007) that is approved for the treatment of pulmonary arterial hypertension (PAH). Selexipag lowered the risk of the primary composite end point of death or a complication related to $\mathrm{PAH}$ in newly treated patients or in patients already treated with one or two other classes of PAH therapies compared with patients who received placebo in the GRIPHON phase 3 clinical trial (Sitbon et al., 2015). Restoration of IP receptor signaling compensates for the reduced production of $\mathrm{PGI}_{2}$ in $\mathrm{PAH}$ (Christman et al., 1992; Tuder et al., 1999) through mechanisms that include vasodilatation and inhibition of exaggerated vascular smooth muscle cell proliferation (Fetalvero et al., 2007; Smyth et al.,

https://doi.org/10.1124/jpet.117.246058.
2009). Selexipag and its active metabolite ACT-333679 [\{4[(5,6-diphenylpyrazin-2-yl)(isopropyl)amino]butoxy\}acetic acid; previously known as MRE-269] have nonprostanoid structures and possess higher selectivity than $\mathrm{PGI}_{2}$ analogs for the IP receptor over other prostanoid receptor subtypes in binding and functional cellular assays (Kuwano et al., 2007; Gatfield et al., 2016). In contrast, $\mathrm{PGI}_{2}$ analogs used in the clinical management of PAH are not selective for the IP receptor and can activate other prostanoid receptor subtypes (Abramovitz et al., 2000; Kuwano et al., 2008; Whittle et al., 2012) as the vasorelaxant efficacy of treprostinil and beraprost, but not selexipag, is reduced via activation of contractile prostaglandin $\mathrm{E}$ receptor $3\left(\mathrm{EP}_{3}\right)$ receptors in the pulmonary artery under conditions associated with PAH (Kuwano et al., 2008; Morrison et al., 2012).

Leg pain is a common side effect in patients receiving treatment with $\mathrm{PGI}_{2}$ analogs and although the effect may be neuropathic in origin (Pagani-Estévez et al., 2017), an additional vascular component can also be considered. Adrenergic

ABBREVIATIONS: $\alpha_{1} \mathrm{AR}, \alpha_{1}$ adrenergic receptor; ACT-333679, \{4-[(5,6-diphenylpyrazin-2-yl)(isopropyl)amino]butoxy\}acetic acid; DBTSA, (2E)-3$\left(3^{\prime}, 4^{\prime}\right.$-dichlorobiphenyl-2-yl)-N-(2-thienylsulfonyl)acrylamide; EFS, electrical field stimulation; $\mathrm{EP}_{3}$, prostaglandin E receptor 3; GR32191B, (4Z)-7[(1R,2R,3S,5S)-5-([1,1'-biphenyl]-4-ylmethoxy)-3-hydroxy-2-(1-piperidinyl)cyclopentyl]-4-hetenoic acid; MCT, monocrotaline; PAH, pulmonary arterial hypertension; $\mathrm{PGF}_{2 \alpha}$, prostaglandin $\mathrm{F}_{2 \alpha}$; $\mathrm{PGl}_{2}$, prostacyclin (IP receptor); $\mathrm{PH}$, pulmonary hypertension; SC51322, 8-chloro-2-[3-[(2furanylmethyl)thio]-1-oxopropyl]hydrazide, dibenz $[b, f][1,4]$ oxazepine-10(11H)-carboxylic acid hydrazide; TP, thromboxane receptor; U46619, 9,11 dideoxy- $9 \alpha, 11 \alpha$-metha-noepoxy prostaglandin $\mathrm{F}_{2 \alpha}$. 
activity is increased in the legs of patients with PAH (VelezRoa et al., 2004) and potent contractile synergy has been reported between $\alpha_{1}$-adrenoceptors and $\mathrm{EP}_{3}$ receptors in preclinical studies (Hung et al., 2006), a phenomenon that could contribute to the peripheral pain reported with $\mathrm{PGI}_{2}$ analogs.

This study tested the hypothesis that selexipag and ACT333679 , unlike nonselective $\mathrm{PGI}_{2}$ analogs (iloprost, beraprost, and treprostinil), cause only relaxation of the femoral artery without paradoxical $\mathrm{EP}_{3}$ receptor-mediated vasoconstriction.

\section{Materials and Methods}

\section{Animals}

Original studies in animals were carried out in accordance with the Guide for the Care and Use of Laboratory Animals as adopted and promulgated by the U.S. National Institutes of Health and were approved by the local Basel-Landschaft cantonal veterinary office (Switzerland). Twelve-week-old male Wistar rats were obtained from the Biotechnology and Animal Breeding Division (Harlan, Füllinsdorf, Switzerland). All rats were housed in climate-controlled conditions with a 12-hour light/dark cycle and had free access to normal pelleted rat chow and drinking water. In certain experiments, pulmonary hypertension $(\mathrm{PH})$ was induced in rats by a single injection of monocrotaline (MCT; $60 \mathrm{mg} / \mathrm{kg}$, i.p.). Vehicle control rats were treated in parallel. Endothelial function was tested 30 days after injection of MCT (Iglarz et al., 2008).

\section{Rat Isolated Femoral Artery}

After euthanasia, rings of the rat femoral artery were prepared using a standard technique. Briefly, the right and left femoral arteries were isolated. Two arterial rings $(1.5 \mathrm{~mm})$ were prepared from each artery, and vessels were suspended between $40-\mu \mathrm{m}$ stainless steel wires in a Mulvany-Halpern myograph system $(10 \mathrm{ml})$ containing modified Krebs-Henseleit buffer with the following composition: $115 \mathrm{mM} \mathrm{NaCl}, 4.7 \mathrm{mM} \mathrm{KCl}, 1.2 \mathrm{mM} \mathrm{MgSO}_{4}, 1.5 \mathrm{mM} \mathrm{KH} \mathrm{KO}_{4}$ $2.5 \mathrm{mM} \mathrm{CaCl}_{2}, 25 \mathrm{mM} \mathrm{NaHCO}_{3}$, and $10 \mathrm{mM}$ glucose. Care was taken to avoid damage to the endothelium. Bathing solution was maintained at $37^{\circ} \mathrm{C}$ and aerated with $95 \% \mathrm{O}_{2} / 5 \% \mathrm{CO}_{2}$ ( $\mathrm{pH} 7.4$ ). An initial resting force of $3.9 \mathrm{mN}$ was applied to the vessel (Duckles et al., 1985), and changes in force generation were measured using an isometric force recorder (Multi Wire Myograph System model 610 M, version 2.2; DMT A/S, Aarhus, Denmark) coupled to a EMKA data acquisition system (EMKA Technologies Inc., Paris, France). Viability of the femoral artery was tested by measuring contraction to $\mathrm{KCl}(60 \mathrm{mM})$ and the presence of a functional endothelium was confirmed by measuring the ability of acetylcholine $(10 \mu \mathrm{M})$ to relax arterial rings contracted with U46619 (9,11-dideoxy-9 $\alpha, 11 \alpha$-metha-noepoxy prostaglandin $\left.\mathrm{F}_{2 \alpha} ; 1 \mu \mathrm{M}\right)$. Mean relaxation to acetylcholine was $81.6 \% \pm$ $1.2 \%$ for all rings tested. In certain experiments, contraction of the femoral artery to electrical field stimulation (EFS) was measured. Arterial rings were placed between platinum electrodes and stimulated every 5 minutes ( $17 \mathrm{~V}, 0.5$-millisecond pulse width, 10 seconds, 4-24 Hz) using an electrical stimulator (EMKA Technologies Inc.). Two frequency-contraction curves were obtained in each vessel: an initial control response, followed (after a period of recovery) by a second curve in the presence of drug vehicle or test compound(s). Contraction in the presence of test compound was expressed as a percentage of the maximal contraction in the first control response.

\section{Rat Isolated Pulmonary Artery}

Rings of the extralobar pulmonary artery were prepared from rats using standard techniques. Vessels were suspended between stainless steel wires in a 10-ml tissue bath set-up and processed in a similar
TABLE 1

Relaxation to acetylcholine $(10 \mu \mathrm{M})$ in the pulmonary and femoral artery from control and MCT-PH rats

Data are presented as the mean \pm S.E.M.

\begin{tabular}{lccc}
\hline \multicolumn{1}{c}{ Group } & Pulmonary Artery & Femoral Artery \\
\hline & & $\%$ & \\
Control & $81.2 \pm 4.2$ & & $82.9 \pm 3.4$ \\
MCT-PH & $25.3 \pm 6.9^{*}$ & & $90.7 \pm 2.3$ \\
\hline
\end{tabular}

$* P<0.0001$ compared with the control pulmonary artery.

manner to that described for the femoral artery. An initial resting force of $4.9 \mathrm{mN}$ was applied to vessels.

\section{Experimental Protocols}

Relaxation of the Pulmonary and Femoral Artery from Control and MCT-PH Rats. Rings of the pulmonary and femoral artery were contracted with phenylephrine $(1 \mu \mathrm{M})$. When the developed force had stabilized, relaxation to acetylcholine $(10 \mu \mathrm{M})$ was measured.

Relaxation of the Femoral Artery. Rings of the femoral artery were contracted with either prostaglandin $\mathrm{F}_{2 \alpha}$ or phenylephrine ( $3.5 \pm$ 0.9 and $3.0 \pm 0.5 \mu \mathrm{M}$, respectively) to give matched submaximal contraction relative to $\mathrm{KCl}(60 \mathrm{mM})(50.8 \% \pm 2.5 \%$ and $50.4 \% \pm 2.7 \%$, respectively). Cumulative concentration-relaxation curves to selexipag, ACT-333679, iloprost, beraprost, or treprostinil were obtained when the developed force had stabilized. The interval between additions of higher concentrations of compounds to the baths was determined by the time required for the response to reach plateau. In experiments that sought to characterize the identity of the receptor mediating responses to test compounds, rings of the femoral artery were exposed to either vehicle or receptor antagonists for 30 minutes prior to obtaining cumulative concentration-response curves to agonists. The choice and concentrations of the following receptor antagonists were based on published data: DBTSA [ $[2 E)-3-\left(3^{\prime}, 4^{\prime}-\right.$ dichlorobiphenyl-2-yl)- $N$-(2-thienylsulfonyl)acrylamide; $\mathrm{EP}_{3}$ receptor] (Gallant et al., 2002; Kuwano et al., 2008), SC51322 (8-chloro-2-[3-[(2furanylmethyl)thio]-1-oxopropyl]hydrazide, dibenz[ $b, f][1,4]$ oxazepine$10(11 H)$-carboxylic acid hydrazide; $\mathrm{EP}_{1}$ receptor) McCormick et al., $2010)$, and GR32191B [(4Z)-7-[(1R,2R,3S,5S)-5-([1,1'-biphenyl]-4-ylmethoxy)3-hydroxy-2-(1-piperidinyl)cyclopentyl]-4-hetenoic acid; thromboxane receptor (TP receptor) TP receptor] (Lumley et al., 1989).

Contraction of the Femoral Artery to EFS. Frequencycontraction curves $(4-24 \mathrm{~Hz})$ were first obtained in the absence or presence of tetrodotoxin $(0.1 \mu \mathrm{M} ; 10$ minutes $)$ and prazosin $(0.1 \mu \mathrm{M}$; 10 minutes) to establish that the smooth muscle contraction was neuronal in origin and mediated via activation of $\alpha_{1} \mathrm{ARs}$ (Zacharia et al., 2004). Contraction of the femoral artery to EFS was abolished by tetrodotoxin $(0.1 \mu \mathrm{M})$ and prazosin $(0.1 \mu \mathrm{M})(n=3$, data not shown).

In separate experiments, the influence of ACT-333679 or treprostinil (both at $10 \mu \mathrm{M}, 20$-minute incubation) on EFS-induced contraction was measured. DBTSA $(1 \mu \mathrm{M})$ and GR32191B $(1 \mu \mathrm{M})$ were added to the bath 20 minutes prior to the addition of treprostinil.

Contraction of the Femoral Artery to Agonists. Cumulative concentration-contraction curves to the $\mathrm{EP}_{1 / 3}$ receptor agonist sulprostone were obtained in rings of the femoral artery. The ability of a subthreshold concentration of sulprostone to contract the femoral artery was measured after exposure of the artery to phenylephrine $\left(0.1 \mu \mathrm{M} ; 10\right.$ minutes), and the role of $\alpha_{1}$-adrenoceptors and $\mathrm{EP}_{3}$ receptors in this response was investigated by prior incubation with either prazosin $(0.1 \mu \mathrm{M} ; 20$ minutes $)$ or DBTSA $(1 \mu \mathrm{M}$; 20 minutes).

\section{Materials}

Selexipag, ACT-333679, and DBTSA were synthesized by Nippon Shinyaku Co. Ltd. (Kyoto, Japan). Iloprost, beraprost, treprostinil, 

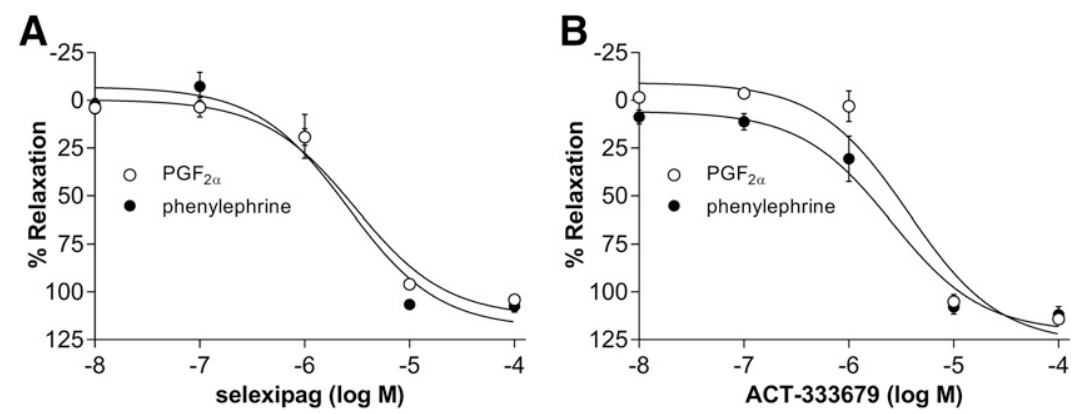

Fig. 1. (A and B) Relaxation to selexipag (A) and ACT333679 (B) in the rat femoral artery contracted with equieffective concentrations of either $\mathrm{PGF}_{2 \alpha}$ or phenylephrine ( $n=6$ /group).

SC51322, and sulprostone were obtained from Cayman Chemical (Ann Arbor, MI). Acetylcholine, GR32191B, phenylephrine, prostaglandin $\mathrm{F}_{2 \alpha}$, and U46619 were purchased from Sigma (St Louis, MO).

\section{Statistical Analyses}

Relaxation of the rat femoral artery to test compounds is expressed as a percentage of the contraction, and contractile responses are expressed as a percentage of the reference contraction to $\mathrm{KCl}(60 \mathrm{mM})$. Results are presented as the mean \pm S.E.M. In some experiments, the S.E.M. values are smaller than the data symbol. $n$ values refer to the number of animals. Best-fit analyses of graphs were performed using GraphPad Prism software (version 7.02 for Windows, www.graphpad.com; GraphPad Software Inc., La Jolla, $\mathrm{CA}) \cdot \mathrm{pEC}_{50}$ values are defined as the negative logarithm of the concentration of agonist that evokes a half maximal response. The effects of receptor antagonists on responses of the femoral artery to analogs of $\mathrm{PGI}_{2}$ were quantified by comparing calculated areas under the agonist concentration-response curves in the absence and presence of antagonists. Calculation of the area under the curve is an integrated analytical method for quantifying the response to an agonist over the whole range of concentrations tested (Hermann et al., 2003; Liang et al., 2010; Morrison et al., 2012). Statistical comparisons between control and treated groups were performed using the paired $t$ test (two-tailed). Differences were considered significant at $P<0.05$.

\section{Results}

\section{Endothelial Function of the Pulmonary and Femoral Artery in MCT-Induced PH Rats}

Relaxation of the extralobar pulmonary and femoral artery to acetylcholine was measured using rings precontracted with the selective $\alpha_{1}$ adrenoceptor $\left(\alpha_{1} \mathrm{AR}\right)$ agonist phenylephrine. Acetylcholine $(10 \mu \mathrm{M})$ relaxed rings of the femoral artery from both control and MCT-PH rats, whereas relaxation of the pulmonary artery to acetylcholine was significantly less in arterial rings from MCT-PH rats (Table 1).

TABLE 2

Relaxation of the femoral artery to selexipag and ACT-333679 Data are presented as the mean \pm S.E.M.

\begin{tabular}{lrr}
\hline Contractile agent & Selexipag & ACT-333679 \\
\hline $\mathrm{pEC}_{50}$ & & \\
$\mathrm{PGF}_{2 \alpha}$ & $5.4 \pm 0.1$ & $5.5 \pm 0.1$ \\
$\mathrm{Phenylephrine}_{E_{\max }}$ & $5.5 \pm 0.1$ & $5.6 \pm 0.1$ \\
$\mathrm{PGF}_{2 \alpha}$ & $113.3 \pm 5.4$ & $126.9 \pm 7.0$ \\
$\mathrm{Phenylephrine}$ & $116.6 \pm 6.6$ & $121.0 \pm 6.6$ \\
\hline
\end{tabular}

\section{Selexipag and ACT-333679 Relax the Femoral Artery}

As femoral arteries from MCT-PH rats displayed a normal endothelial function, the remaining experiments were conducted in femoral arteries from healthy Wistar rats. The effects of selexipag and its metabolite ACT-333679 on isometric force development in the rat femoral artery were measured using rings precontracted with equi-effective concentrations of either prostaglandin $\mathrm{F}_{2 \alpha}\left(\mathrm{PGF}_{2 \alpha}\right)$ or the selective $\alpha_{1} \mathrm{AR}$ agonist phenylephrine. Both selexipag (Fig. 1A) and ACT-333679 (Fig. 1B) relaxed the femoral artery. No statistically significant difference in relaxation (area under the curve) to either selexipag or ACT-333679 was observed in the femoral artery contracted with $\mathrm{PGF}_{2 \alpha}$ or phenylephrine (Fig. 1; Table 2). EFS (4-24 Hz) contracted the femoral artery via endogenously released norepinephrine (Fig. 2). The maximum contraction under control conditions was $91.1 \% \pm 7.6 \%$ relative to $\mathrm{KCl}(60 \mathrm{mM})$. ACT-333679 $(10 \mu \mathrm{M})$ significantly inhibited contraction of the femoral artery by EFS (4-24 Hz; area under the curve: $1234 \pm 135.9$ and $580.8 \pm 69.3$ for the control and ACT-333679, respectively; $P<0.05, n=6$; Fig. 2).

\section{$\mathrm{PGI}_{2}$ Analogs Constrict the Femoral Artery}

The effects of $\mathrm{PGI}_{2}$ analogs on the rat femoral artery were compared with those of selexipag and ACT-333679 in rings precontracted with equi-effective concentrations of either $\mathrm{PGF}_{2 \alpha}$ or phenylephrine. Although iloprost, beraprost, and treprostinil evoked concentration-dependent relaxation of the femoral artery contracted with $\mathrm{PGF}_{2 \alpha}$ (Fig. 3), these $\mathrm{PGI}_{2}$ analogs did not cause vasorelaxation but rather induced further contraction in femoral arterial rings precontracted with phenylephrine (Fig. 3). The maximum contraction to

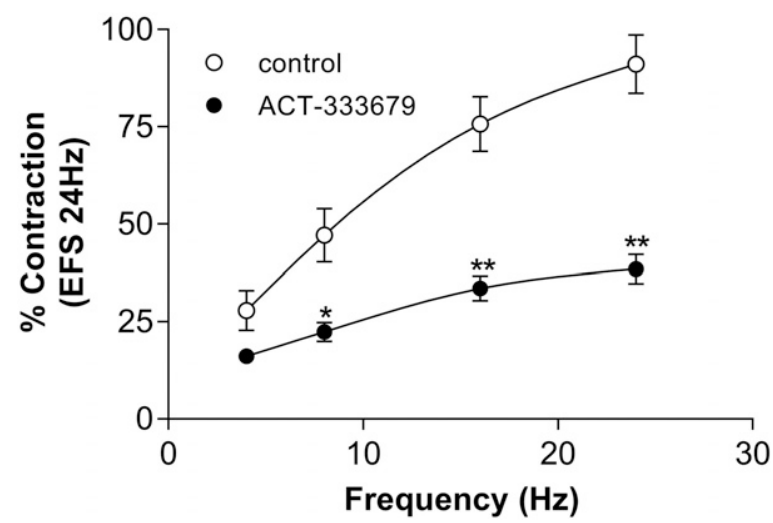

Fig. 2. Effect of ACT-333679 $(10 \mu \mathrm{M})$ on contraction of the rat femoral artery to EFS. $* P<0.05 ; * * P<0.01$ ( $n=6$ /group). 

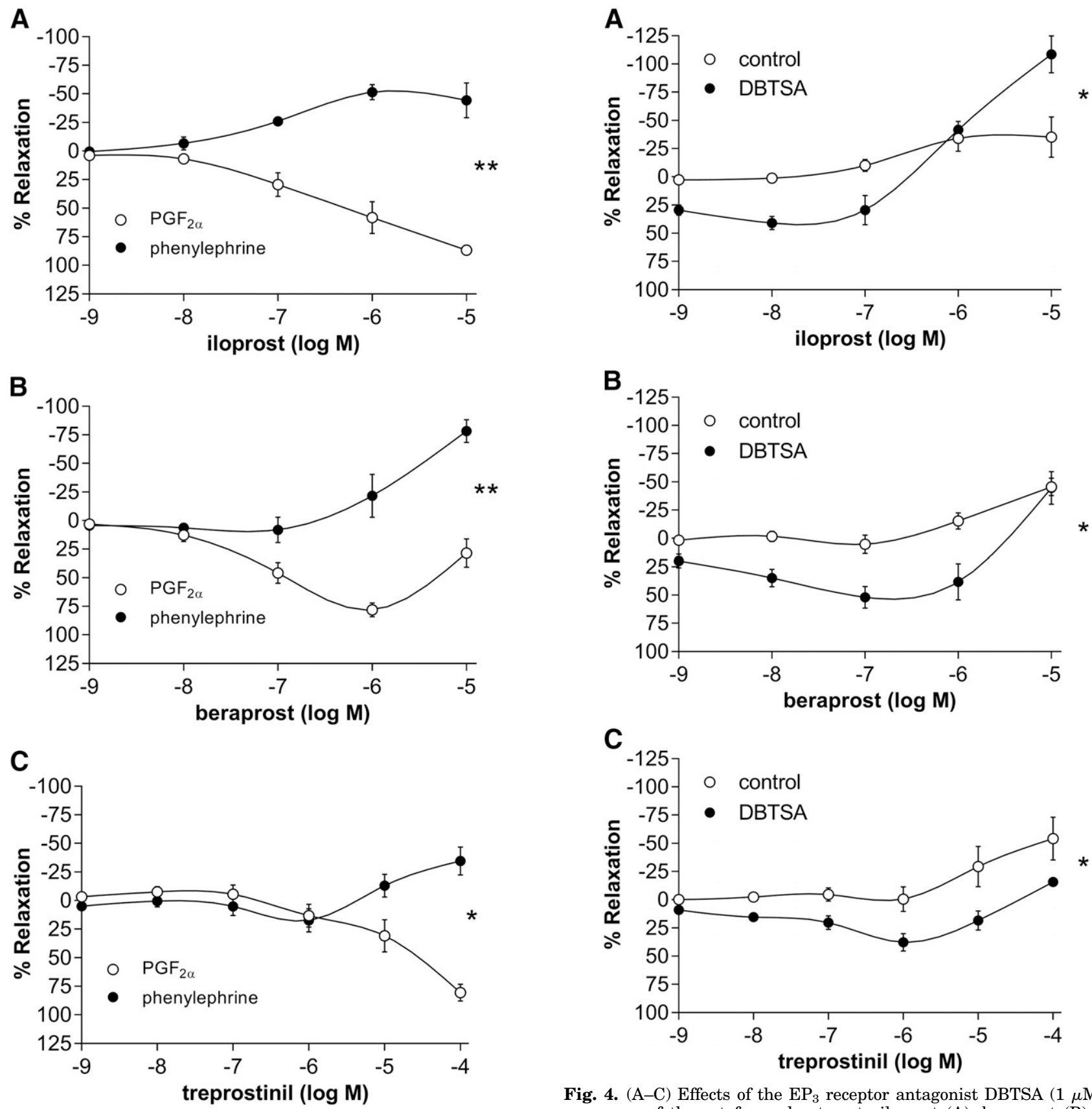

Fig. 3. (A-C) Responses to iloprost (A), beraprost (B), and treprostinil (C) in the rat femoral artery contracted with equi-effective concentrations of either $\mathrm{PGF}_{2 \alpha}$ or phenylephrine. ${ }^{*} P<0.05$ for comparison of area under the curve values at concentrations above $1 \mu \mathrm{M} ; * * P<0.01$ for comparison of area under the curve values over the full range of concentrations tested $(n=6$ /group $)$.

iloprost, beraprost, and treprostinil was $44.4 \% \pm 15.1 \%, 78.4 \%$ $\pm 9.8 \%$, and $34.6 \% \pm 12.1 \%$, respectively. Differences in area under the curve values for responses to iloprost and beraprost (over the full range of concentrations tested) were statistically significant ( $P<0.05, n=6$; Fig. $3, \mathrm{~A}$ and $\mathrm{B})$, whereas area under the curve values for responses to treprostinil were significantly different only at concentrations above $1 \mu \mathrm{M}$ $(P<0.05, n=6$; Fig. $3 \mathrm{C})$.

Iloprost, beraprost, and treprostinil caused weak vasorelaxation of the femoral artery contracted with phenylephrine in

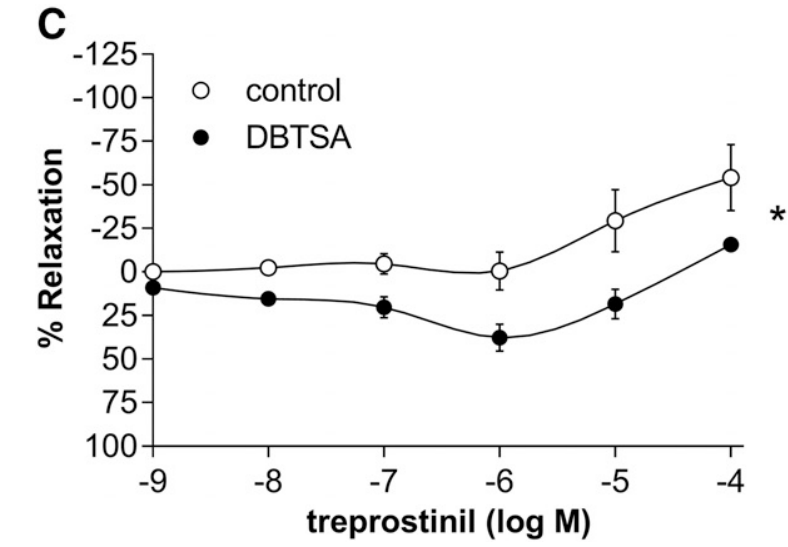

Fig. 4. (A-C) Effects of the $\mathrm{EP}_{3}$ receptor antagonist DBTSA $(1 \mu \mathrm{M})$ on responses of the rat femoral artery to iloprost (A), beraprost (B), and treprostinil (C). Arterial rings were contracted with phenylephrine. $* P<0.05$ for comparison of area under the curve values ( $n=5$ /group).

the presence of the $\mathrm{EP}_{3}$ receptor antagonist (DBTSA, $1 \mu \mathrm{M}$ ) (Fig. 4). Relaxation to iloprost, beraprost, and treprostinil was $40.8 \% \pm 5.6 \%, 51.8 \% \pm 9.3 \%$, and $37.6 \% \pm 7.4 \%$, respectively. Differences in area under the curve values for responses to all $\mathrm{PGI}_{2}$ analogs tested in the absence and presence of DBTSA were statistically significant $(P<0.05, n=5$; Fig. 4). Antagonism of $\mathrm{EP}_{1}(\mathrm{SC} 51322,1 \mu \mathrm{M})$ and TP (GR32191B, 0.1 $\mu \mathrm{M})$ receptors did not significantly modulate the reactivity of the femoral artery to $\mathrm{PGI}_{2}$ analogs (Table 3 ).

In direct contrast to ACT-333679, treprostinil $(10 \mu \mathrm{M})$ significantly increased contraction to EFS (maximum contraction: $94.5 \% \pm 10.2 \%$ and $188.6 \% \pm 9.2 \%$ for the control and treprostinil, respectively; $P<0.05, n=4$; Fig. 5). This 
TABLE 3

Effect of SC51322 and GR32191B on responses of the femoral artery to $\mathrm{PGI}_{2}$ analogs

Data are presented as the mean \pm S.E.M. area under the curve.

\begin{tabular}{lccc}
\hline \multicolumn{1}{c}{ Group } & Iloprost & Beraprost & Treprostinil \\
\hline Control & $684.7 \pm 50.7$ & $742.5 \pm 44.2$ & $822.5 \pm 47.7$ \\
SC51322 & $704.1 \pm 44.5$ & $769.1 \pm 25.6$ & $841.0 \pm 43.7$ \\
Control & $752.4 \pm 21.2$ & $729.4 \pm 17.3$ & $870.0 \pm 27.0$ \\
GR32191B & $724.6 \pm 28.3$ & $756.7 \pm 14.0$ & $857.2 \pm 12.5$ \\
\hline
\end{tabular}

augmented contraction was significantly reduced by the $\mathrm{EP}_{3}$ receptor antagonist DBTSA, with area under the curve values of $1398 \pm 162.5$ and $2586 \pm 199.6$ for the control and treprostinil, respectively $(P<0.01)$ compared with $1512 \pm$ 376.8 for treprostinil and DBTSA $(P<0.05$ vs. treprostinil alone; $n=4$; Fig. 5). Antagonism of TP receptors with GR32191B (1 $\mu \mathrm{M})$ did not significantly inhibit the effect of treprostinil on contraction to EFS, with area under the curve values of $1398 \pm 162.5$ and $2470 \pm 182.3$ for the control and treprostinil $(P<0.01)$, respectively, and $1954 \pm 374.5$ for treprostinil and GR32191B $(P>0.05$ vs. treprostinil alone, $n=4)$

\section{$\alpha_{1}$ ARs and EP ${ }_{3}$ Receptors Act Synergistically in the Femoral Artery}

Since reactivity of the femoral artery to $\mathrm{PGI}_{2}$ analogs was only modulated during $\alpha_{1} \mathrm{AR}$ stimulation, the potential pharmacological interaction between contractile $\mathrm{EP}_{3}$ receptors and $\alpha_{1} \mathrm{ARs}$ was investigated. The $\mathrm{EP}_{1 / 3}$ receptor agonist sulprostone caused concentration-dependent contraction of the rat femoral artery (Fig. $6 \mathrm{~A} ; \mathrm{pEC}_{50}=6.4 \pm 0.3, E_{\max }=140.6 \% \pm$ $15.6 \%$ ). Sulprostone at a concentration that did not cause contraction by itself (subthreshold concentration of $1 \mathrm{nM}$ ) was able to contract the femoral artery in the presence of phenylephrine $(0.1 \mu \mathrm{M})$ (Fig. 6B). Next, the identity of the receptor subtype involved in the exaggerated contraction to sulprostone in the presence of phenylephrine was determined. $\mathrm{EP}_{3}$ receptor antagonist DBTSA $(1 \mu \mathrm{M})$ and prazosin $(0.1 \mu \mathrm{M}$; selective $\alpha_{1} \mathrm{AR}$ antagonist) significantly reduced sulprostoneevoked contraction (Fig. 6B). Selective $\mathrm{EP}_{1}$ receptor antagonist SC51322 $(1 \mu \mathrm{M})$ did not inhibit contraction to sulprostone $(47.4 \% \pm 10.5 \%$ and $38.5 \% \pm 6.9 \%$ for the control and treated groups, respectively; $P>0.05, n=4$ ).

\section{Discussion}

The results of this study demonstrate the functional impact of the selectivity of selexipag and its metabolite for the IP receptor over other prostanoid receptors. Relaxation of the femoral artery to selexipag and ACT-333679 is not modulated by coactivation of contractile $\mathrm{EP}_{3}$ receptors, nor is it dependent on the nature of the contractile agent used to raise vascular tone. In contrast, $\mathrm{PGI}_{2}$ analogs activate $\mathrm{EP}_{3}$ receptors to contract the femoral artery in the presence of phenylephrine, and treprostinil augments contraction to nerve-released norepinephrine.

We established that endothelial function was preserved in the femoral, but not pulmonary, artery from MCT-PH rats, demonstrating the vascular selectivity of this $\mathrm{PH}$ model. Further experiments using the femoral artery were therefore

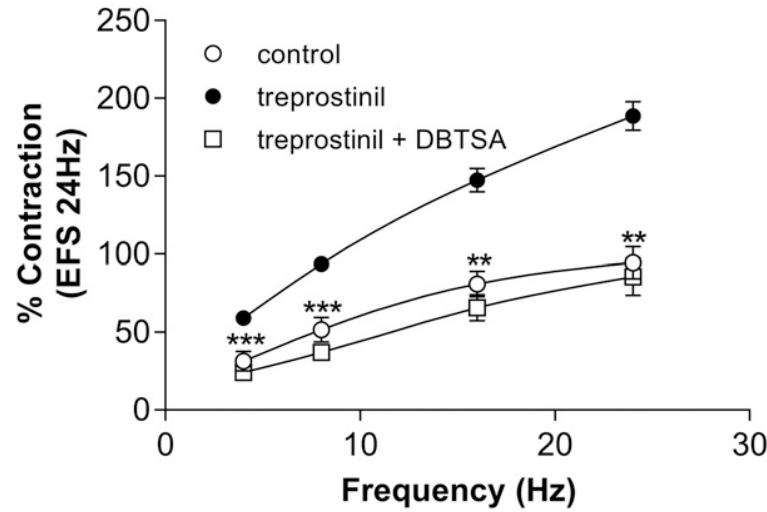

Fig. 5. Effect of treprostinil $(10 \mu \mathrm{M})$ on contraction of the rat femoral artery to EFS in the absence and presence of the $\mathrm{EP}_{3}$ receptor antagonist DBTSA. $* * P<0.01 ; * * * P<0.001$ ( $n=6$ /group).

performed in the presence of a functional vascular endothelium. The femoral artery was chosen for investigation since its occlusion contributes to leg pain in patients with peripheral artery disease (Beard 2000). This artery is also predominantly used in preclinical models of leg ischemia (Krishna et al., 2016; Queme et al., 2017).

Vasorelaxation of the femoral artery to selexipag and ACT333679 was similar in rings precontracted with either $\mathrm{PGF}_{2 \alpha}$ or the $\alpha_{1} \mathrm{AR}$ agonist phenylephrine. These data are in good agreement with previous findings in the pulmonary artery (Kuwano et al., 2008; Morrison et al., 2012). Reactivity to analogs of $\mathrm{PGI}_{2}$ was markedly different from that measured in response to selexipag and ACT-333679. $\mathrm{PGI}_{2}$ analogs relaxed the femoral artery precontracted with $\mathrm{PGF}_{2 \alpha}$ but caused further contraction of the femoral artery precontracted with phenylephrine. This augmented contraction to $\mathrm{PGI}_{2}$ analogs might be caused by activation of contractile $\mathrm{EP}_{3}$ receptors, since antagonism of $\mathrm{EP}_{3}$ receptors revealed modest relaxation to all $\mathrm{PGI}_{2}$ analogs tested. Contraction of the femoral artery to $\mathrm{PGI}_{2}$ analogs measured during $\alpha_{1} \mathrm{AR}$ activation contrasted with the weak relaxation observed under the same conditions in pulmonary artery (Morrison et al., 2012). These data suggest an important synergy between $\mathrm{EP}_{3}$ receptors and the adrenergic system in the femoral artery.

Differential effects of ACT-333679 and analogs of $\mathrm{PGI}_{2}$ were also observed after transmural sympathetic nerve stimulation. ACT-333679, at a concentration that evoked maximal relaxation of the femoral artery, inhibited arterial contraction to EFS. This inhibitory effect of ACT-333679 is considered to be mediated via postsynaptic IP receptors in a manner similar to that observed for $\mathrm{PGI}_{2}$ in the rabbit mesenteric artery (Armstrong et al., 1979). The same concentration of treprostinil, however, significantly augmented contraction to EFS in an $\mathrm{EP}_{3}$ receptor-dependent manner. Sensitivity of EFSinduced contraction to tetrodotoxin and prazosin confirmed the nerve origin and critical involvement of $\alpha_{1} \mathrm{ARs}$ in this response (Zacharia et al., 2004). Thus, the ability of treprostinil to augment contraction of the femoral artery to endogenously released norepinephrine is consistent with postsynaptic interplay between $\alpha_{1} \mathrm{ARs}$ and $\mathrm{EP}_{3}$ receptors.

Marked contractile synergy between $\mathrm{EP}_{3}$ receptors and $\alpha_{1} \mathrm{ARs}$ has been described in the rat femoral artery (Hung et al., 2006). This artery receives dense sympathetic innervation and possesses high norepinephrine content (Todd 1980; 


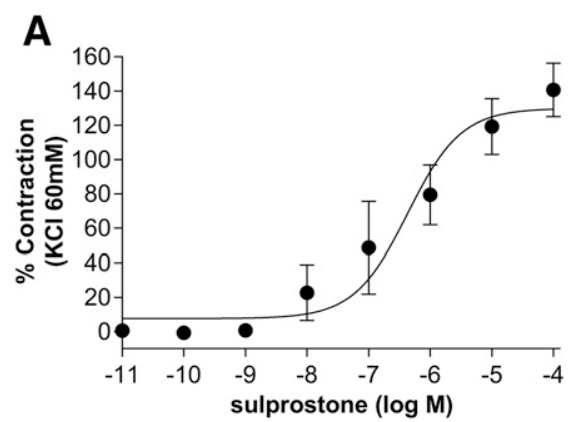

Fig. 6. Contraction of the rat femoral artery to sulprostone in the absence or presence of phenylephrine. (A) Sulprostone causes concentration-dependent contraction of the femoral artery. (B) A subthreshold concentration of sulprostone $(1 \mathrm{nM})$ contracts the femoral artery in the presence of phenylephrine $(0.1 \mu \mathrm{M})$. DBTSA $(1 \mu \mathrm{M})$ and prazosin $(0.1 \mu \mathrm{M})$ inhibit contraction to sulprostone in the presence of phenylephrine. ${ }^{*} P<0.05 ; * * P<0.01$ ( $n=6$ /group).
Duckles et al., 1985; Stassen et al., 1998). Thus, the femoral artery is suitable for study of the potential pharmacological interplay between $\mathrm{EP}_{3}$ receptors and $\alpha_{1} \mathrm{ARs}$ and its effect on vascular responsiveness to selexipag and analogs of $\mathrm{PGI}_{2}$. Synergy between $\alpha_{1} \mathrm{ARs}$ and $\mathrm{EP}_{3}$ receptors in the femoral artery was further supported by the observations that a subthreshold concentration of the $\mathrm{EP}_{1 / 3}$ receptor agonist sulprostone evoked significant contraction of the femoral artery only in the presence of phenylephrine. Activation of both $\mathrm{EP}_{3}$ and $\alpha_{1} \mathrm{ARs}$ receptors was required, since contraction to sulprostone was abolished by either DBTSA or prazosin. The contractile synergy between femoral $\mathrm{EP}_{3}$ receptors and $\alpha_{1}$ ARs described here and by others (Hung et al., 2006) may contribute to the well documented peripheral muscle pain (myalgia) reported in patients with $\mathrm{PAH}$ receiving treatment with $\mathrm{PGI}_{2}$ analogs (Tapson et al., 2012, 2013; Pagani-Estévez et al., 2017). Involvement of other lower limb arteries that are under adrenergic control (e.g., the popliteal artery) (Sada et al., 1985) cannot be excluded. Although the development of pain is considered to arise from IP and $\mathrm{EP}_{3}$ receptor-dependent sensitization of sensory afferent neurons (Nakae et al., 2005; Southall and Vasko, 2001), our data support an additional vascular mechanism. Leg ischemia is commonly associated with pain in the calf and thigh muscles while walking, due to restriction of blood flow through the femoral artery (Beard 2000). In addition, reduced blood flow and tissue oxygenation, as occur after exaggerated vasoconstriction, promote the production of metabolism-derived pain mediators (Queme et al., 2017).

The high selectivity of selexipag and its metabolite for the prostacyclin IP receptor precludes $\mathrm{EP}_{3}$ receptor-mediated vasoconstriction and sensitization of afferent neurons, which might translate into improved tolerability over $\mathrm{PGI}_{2}$ analogs in patients with $\mathrm{PAH}$. In conclusion, this study described differences in the pharmacology of the selective prostacyclin IP receptor agonists selexipag and ACT-333679 and nonselective analogs of $\mathrm{PGI}_{2}$ in the rat femoral artery. Selexipag and ACT-333679 relaxed the femoral artery, whereas $\mathrm{EP}_{3}$ receptor-mediated contraction to $\mathrm{PGI}_{2}$ analogs was exacerbated during $\alpha_{1} \mathrm{AR}$ stimulation.

\section{Authorship Contributions}

Participated in research design: Morrison, Iglarz, Clozel.

Conducted experiments: Haag, Ernst.

Performed data analysis: Morrison, Haag, Ernst.

Wrote or contributed to the writing of the manuscript: Morrison, Iglarz, Clozel.

\section{References}

Abramovitz M, Adam M, Boie Y, Carrière M, Denis D, Godbout C, Lamontagne S, Rochette C, Sawyer N, Tremblay NM, et al. (2000) The utilization of recombinant prostanoid receptors to determine the affinities and selectivities of prostaglandins and related analogs. Biochim Biophys Acta 1483:285-293.

Armstrong JM, Thirsk G, and Salmon JA (1979) Effects of prostacyclin (PGI2), 6-oxoPGF1 alpha and PGE2 on sympathetic nerve function in mesenteric arteries and veins of the rabbit in vitro. Hypertension 1:309-315.

Beard JD (2000) ABC of arterial and venous disease: chronic lower limb ischemia. BMJ 320:854-857.

Christman BW, McPherson CD, Newman JH, King GA, Bernard GR, Groves BM, and Loyd JE (1992) An imbalance between the excretion of thromboxane and prostacyclin metabolites in pulmonary hypertension. $N$ Engl $J$ Med 327:70-75.

Duckles SP, Carter BJ, and Williams CL (1985) Vascular adrenergic neuroeffector function does not decline in aged rats. Circ Res 56:109-116.

Fetalvero KM, Martin KA, and Hwa J (2007) Cardioprotective prostacyclin signaling in vascular smooth muscle. Prostaglandins Other Lipid Mediat 82:109-118.

Gallant M, Carrière MC, Chateauneuf A, Denis D, Gareau Y, Godbout C, Greig G, Juteau H, Lachance N, Lacombe P, et al. (2002) Structure-activity relationship of biaryl acylsulfonamide analogues on the human $\left.\mathrm{EP}_{3}\right)$ prostanoid receptor. Bioorg Med Chem Lett 12:2583-2586.

Gatfield J, Menyhart K, Tunis M, Studer R, Ferrari G, and Nayler O (2016) Selectivity of the selexipag active metabolite ACT-333679 for the IP receptor avoids DP1/EP2-mediated inhibition of natural killer cell responses in vitro. Am J Respir Crit Care Med 193:A2238.

Hermann M, Camici G, Fratton A, Hurlimann D, Tanner FC, Hellermann JP, Fiedler M, Thiery J, Neidhart M, Gay RE, et al. (2003) Differential effects of selective cyclooxygenase-2 inhibitors on endothelial function in salt-induced hypertension. Circulation 108:2308-2311.

Hung GHY, Jones RL, Lam FFY, Chan KM, Hidaka H, Suzuki M, and Sasaki Y (2006) Investigation of the pronounced synergism between prostaglandin $\mathrm{E}_{2}$ and other constrictor agents on rat femoral artery. Prostaglandins Leukot Essent Fatty Acids 74:401-415.

Iglarz M, Binkert C, Morrison K, Fischli W, Gatfield J, Treiber A, Weller T, Bolli MH Boss C, Buchmann S, et al. (2008) Pharmacology of macitentan, an orally active tissue-targeting dual endothelin receptor antagonist. J Pharmacol Exp Ther 327: $736-745$.

Krishna SM, Omer SM, and Golledge J (2016) Evaluation of the clinical relevance and limitations of current pre-clinical models of peripheral artery disease. Clin Sci (Lond) 130:127-150.

Kuwano K, Hashino A, Asaki T, Hamamoto T, Yamada T, Okubo K, and Kuwabara K (2007) 2-[4-[(5,6-diphenylpyrazin-2-yl)(isopropyl)amino]butoxy]-N-(methylsulfonyl)acetamide (NS-304), an orally available and long-acting prostacyclin receptor agonist prodrug. J Pharmacol Exp Ther 322:1181-1188.

Kuwano K, Hashino A, Noda K, Kosugi K, and Kuwabara K (2008) A long-acting and highly selective prostacyclin receptor agonist prodrug, 2-4-[(5,6-diphenylpyrazin-2yl)(isopropyl)aminolbutoxy-N-(methylsulfonyl)acetamide (NS-304), ameliorates rat pulmonary hypertension with unique relaxant responses of its active form, 4 -[(5,6diphenylpyrazin-2-yl)(isopropyl)amino]butoxyacetic acid (MRE-269), on rat pulmonary artery. J Pharmacol Exp Ther 326:691-699.

Liang CF, Au ALS, Leung SWS, Ng KFJ, Félétou M, Kwan YW, Man RYK and Vanhoutte PM (2010) Endothelium-derived nitric oxide inhibits the relaxation of the porcine coronary artery to natriuretic peptides by desensitizing big conductance calcium-activated potassium channels of vascular smooth muscle. $J$ Pharmacol Exp Ther 334:223-231.

Lumley P, White BP, and Humphrey PPA (1989) GR32191, a highly potent and specific thromboxane $\mathrm{A}_{2}$ receptor blocking drug on platelets and vascular and airways smooth muscle in vitro. Br J Pharmacol 97:783-794.

McCormick C, Jones RL, Kennedy S, and Wadsworth RM (2010) Activation of prostanoid EP receptors by prostacyclin analogues in rabbit iliac artery: implications for anti-restenotic potential. Eur J Pharmacol 641:160-167.

Morrison K, Studer R, Ernst R, Haag F, Kauser K, and Clozel M (2012) Differential effects of Selexipag [corrected] and prostacyclin analogs in rat pulmonary artery. $J$ Pharmacol Exp Ther 343:547-555.

Nakae K, Saito K, Iino T, Yamamoto N, Wakabayashi M, Yoshikawa S, Matsushima $\mathrm{S}$, Miyashita H, Sugimoto H, Kiba A, et al. (2005) A prostacyclin receptor antagonist inhibits the sensitized release of substance $\mathrm{P}$ from rat sensory neurons. $J$ Pharmacol Exp Ther 315:1136-1142. 
Pagani-Estévez GL, Swetz KM, McGoon MD, Frantz RP, Tointon SK, Karnyski AM, Durst LA, and Watson JC (2017) Characterization of prostacyclin-associated leg pain in patients with pulmonary arterial hypertension. Ann Am Thorac Soc 14 206-212.

Queme LF, Ross JL, and Jankowski MP (2017) Peripheral mechanisms of ischemic myalgia. Front Cell Neurosci 11:419.

Sada K, Ninomiya I, Imanishi K, Iwaki Y, and Shirai M (1985) Non-uniform effects of neurohumoral agents on the internal diameter in parallel and series arranged small arteries in rabbit hindlimb. Jpn J Physiol 35:321-334.

Sitbon O, Channick R, Chin KM, Frey A, Gaine S, Galiè N, Ghofrani HA, Hoeper MM, Lang IM, Preiss R, et al.; GRIPHON Investigators (2015) Selexipag for the treatment of pulmonary arterial hypertension. $N$ Engl J Med 373: $2522-2533$.

Smyth EM, Grosser T, Wang M, Yu Y, and FitzGerald GA (2009) Prostanoids in health and disease. J Lipid Res 50 (Suppl):S423-S428.

Southall MD and Vasko MR (2001) Prostaglandin receptor subtypes, EP3C and EP4 mediate the prostaglandin $\mathrm{E}_{2}$-induced cAMP production and sensitization of sensory neurons. J Biol Chem 276:16083-16091.

Stassen FRM, Maas RGHT, Schiffers PMH, Janssen GMJ, and De Mey JGR (1998) A positive and reversible relationship between adrenergic nerves and alpha-1A adrenoceptors in rat arteries. J Pharmacol Exp Ther 284:399-405.

Tapson VF, Jing ZC, Xu KF, Pan L, Feldman J, Kiely DG, Kotlyar E, McSwain CS, Laliberte K, Arneson C, et al.; FREEDOM-C2 Study Team (2013) Oral treprostinil for the treatment of pulmonary arterial hypertension in patients receiving background endothelin receptor antagonist and phosphodiesterase type 5 inhibitor therapy (the FREEDOM-C2 study): a randomized controlled trial. Chest 144: 952-958.
Tapson VF, Torres F, Kermeen F, Keogh AM, Allen RP, Frantz RP, Badesch DB, Frost AE, Shapiro SM, Laliberte K, et al. (2012) Oral treprostinil for the treatment of pulmonary arterial hypertension in patients on background endothelin receptor antagonist and/or phosphodiesterase type 5 inhibitor therapy (the FREEDOM-C study): a randomized controlled trial. Chest 142:1383-1390.

Todd ME (1980) Development of adrenergic innervation in rat peripheral vessels: a fluorescence microscopic study. J Anat 131:121-133.

Tuder RM, Cool CD, Geraci MW, Wang J, Abman SH, Wright L, Badesch D, and Voelkel NF (1999) Prostacyclin synthase expression is decreased in lungs from patients with severe pulmonary hypertension. Am J Respir Crit Care Med 159: 1925-1932.

Velez-Roa S, Ciarka A, Najem B, Vachiery JL, Naeije R, and van de Borne P (2004) Increased sympathetic nerve activity in pulmonary artery hypertension. Circulation 110:1308-1312.

Whittle BJ, Silverstein AM, Mottola DM, and Clapp LH (2012) Binding and activity of the prostacyclin receptor (IP) agonists, treprostinil and iloprost, at human prostanoid receptors: treprostinil is a potent $\mathrm{DP}_{1}$ and $\mathrm{EP}_{2}$ agonist. Biochem Pharmacol 84:68-75.

Zacharia J, Hillier C, and MacDonald A (2004) Alpha1-adrenoceptor subtypes involved in vasoconstrictor responses to exogenous and neurally released noradrenaline in rat femoral resistance arteries. Br J Pharmacol 141:915-924.

Address correspondence to: Keith Morrison, Drug Discovery Department, Idorsia Pharmaceuticals Ltd., Hegenheimermattweg 91, Allschwil CH4123, Switzerland. E-mail: keith.morrison@idorsia.com 